\title{
Anticoagulation-associated adverse drug events
}

\author{
Gregory Piazza, MD ${ }^{\mathrm{a}}$, Thanh Nha Nguyen, PharmD ${ }^{\mathrm{b}}$, Deborah Cios, PharmD ${ }^{\mathrm{c}}$, Matthew \\ Labreche, PharmD ${ }^{d}$, Benjamin Hohlfelder ${ }^{\mathrm{e}}$, John Fanikos, RPh, MBA ${ }^{\dagger}$, Karen Fiumara, \\ PharmDg, and Samuel Z. Goldhaber, MD ${ }^{h}$ \\ Cardiovascular Division, Department of Medicine, Brigham and Women's Hospital, Harvard \\ Medical School, Boston, MA, USA
}

\begin{abstract}
Purpose-Anticoagulant drugs are among the most common medications that cause adverse drug events (ADEs) in hospitalized patients. We performed a five-year retrospective study at Brigham and Women's Hospital to determine clinical characteristics, types, root causes, and outcomes of anticoagulant-associated adverse drug events (ADEs).
\end{abstract}

Methods-We reviewed all inpatient anticoagulant-associated ADEs, including adverse drug reactions (ADRs) and medication errors, reported at Brigham and Women's Hospital through the Safety Reporting System from May 2004 to May 2009. We also collected data regarding the cost associated with hospitalizations in which ADRs occurred.

Results-Of 463 anticoagulant-associated ADEs, 226 were MEs (48.8\%), 141 were ADRs (30.5\%), and 96 (20.7\%) involved both a medication error and ADR. Seventy percent of anticoagulant-associated ADEs were potentially preventable. Transcription errors (48\%) were the most frequent root cause of anticoagulant-associated medication errors, while medication errors (40\%) were a common root cause of anticoagulant-associated ADRs. Death within 30 days of anticoagulant-associated ADEs occurred in $11 \%$ of patients. After an anticoagulant-associated ADR, most hospitalization expenditures were attributable to nursing costs (mean $\$ 33,189$ per ADR) followed by pharmacy costs (mean $\$ 7,451$ per ADR).

Conclusion-Most anticoagulant-associated ADEs among inpatients result from medication errors and are therefore potentially preventable. We observed an elevated 30-day mortality rate among patients who suffered an anticoagulant-associated ADE and high hospitalization costs following ADRs. Further Quality Improvement efforts to reduce anticoagulant-associated medication errors are warranted to improve patient safety and decrease health care expenditures.

(C) 2011 Elsevier Inc. All rights reserved.

Address for Correspondence: Gregory Piazza, MD, Cardiovascular Division, Brigham and Women's Hospital, 75 Francis St., Boston, MA 02115, Tel: (617) 732-6986, Fax: (617) 738-7652, gpiazza@ partners.org.

${ }^{a}$ Cardiovascular Division, Department of Medicine, Brigham and Women's Hospital, Harvard Medical School, Boston, MA, USA. Nothing to disclose.

bVenous Thromboembolism Research Group, Brigham and Women's Hospital, Boston, MA, USA. Nothing to disclose.

cDepartment of Pharmacy, Brigham and Women's Hospital, Boston, MA, USA. Nothing to disclose.

dVenous Thromboembolism Research Group, Brigham and Women's Hospital, Boston, MA, USA. Nothing to disclose.

eVenous Thromboembolism Research Group, Brigham and Women's Hospital, Boston, MA, USA. Nothing to disclose.

f Department of Pharmacy, Brigham and Women's Hospital, Boston, MA, USA. Nothing to disclose.

gCenter for Clinical Excellence, Brigham and Women's Hospital, Boston, MA, USA. Nothing to disclose.

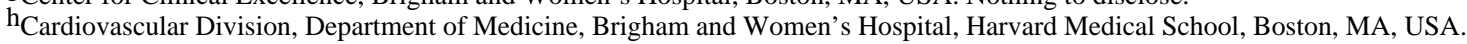

Nothing to disclose.

Publisher's Disclaimer: This is a PDF file of an unedited manuscript that has been accepted for publication. As a service to our customers we are providing this early version of the manuscript. The manuscript will undergo copyediting, typesetting, and review of the resulting proof before it is published in its final citable form. Please note that during the production process errors may be discovered which could affect the content, and all legal disclaimers that apply to the journal pertain. 


\section{Keywords}

adverse drug events; adverse drug reactions; anticoagulation; medication errors

Adverse drug events (ADEs), which comprise medication errors and adverse drug reactions (ADRs), represent a major source of harm among hospitalized patients and have been a driving force behind implementation of Electronic Health Records (EHRs) including computerized provider order entry. ${ }^{1-6}$ One study reported that 6.5 medication-related adverse events occurred per 100 hospitalizations and estimated that more than one-quarter of these events were the result of a medication error. ${ }^{7}$ Medication errors are potentially preventable causes of ADRs that can occur at all stages of the medication process, including prescription, transcription, dispensing, and administration. ${ }^{8-12}$ Compared with nonpreventable events, potentially preventable ADEs have been shown to double the incremental additional length of stay and health care costs attributable to the event. ${ }^{13}$

Anticoagulant drugs, including warfarin, unfractionated heparin, and low-molecular weight heparin, are among the most commonly implicated medications that cause ADEs in hospitalized patients. $1,4,6,11,14$ Despite implementation of computerized provider order entry, electronic medication administration records, and improved infusion pump technology ("smart pumps"), medication errors involving anticoagulant medications remain common. ${ }^{11,12}$ Elderly ${ }^{15,16}$ and cardiac patients ${ }^{14}$ represent populations at particularly high risk for suffering anticoagulant-associated ADRs.

To determine the clinical characteristics, types, severity, root causes, and outcomes of anticoagulant-associated ADEs, we performed a five-year retrospective study of the Safety Reporting System at Brigham and Women's Hospital. We reviewed discrete ADEs that originated during hospitalization at Brigham and Women's Hospital. We also conducted an analysis of the cost associated with hospitalizations in which ADRs occurred.

\section{Methods}

\section{Patient population}

Brigham and Women's Hospital is a 793-bed acute tertiary care facility providing medical and surgical care for patients with general medical, cardiothoracic, orthopedic, oncologic, neurologic, obstetric and gynecologic, neonatal, urologic, and gastrointestinal conditions. Brigham and Women's Hospital utilizes a Medical Informatics System that integrates an online medical record, computerized provider order entry, an electronic medication administration record, and an electronic safety reporting system. The Safety Reporting System is a voluntary computerized reporting system for ADRs and medication errors that was instituted in May 2004.

\section{Data collection}

We reviewed all inpatient anticoagulant-associated ADEs, including ADRs and medication errors, reported at Brigham and Women's Hospital through the Safety Reporting System from May 2004 to May 2009. Inpatient events for the purpose of our study were required to have originated during hospitalization at Brigham and Women's Hospital. We excluded reported anticoagulant-associated ADEs that took place in the Emergency Department, Operating Room, Cardiac Catheterization Laboratory, Cardiovascular Recovery Room, Post-Anesthesia Care Unit (PACU), and Neonatal Intensive Care Unit (NICU) because medication administration records were not consistently computerized in these units during the registry period. We defined an ADR as a response to a drug normally used for prophylaxis or therapy of disease and that was noxious and unintended. ${ }^{17}$ A medication 
error was defined as an event that caused or led to inappropriate medication use or patient harm. ${ }^{17} \mathrm{~A}$ medication error that was discovered and corrected before reaching the patient was classified as a near miss. All isolated medication errors and ADRs that resulted from medication errors were considered potentially preventable.

We searched the Safety Reporting System using Risk Monitor Pro (rL Solutions, Inc., Cambridge, MA). We evaluated the patient characteristics, ADE type and severity, root cause, and outcomes of all anticoagulation-associated medication errors and ADRs. All patient records were reviewed for evidence of treatment with an anticoagulant medication. Hemorrhagic events were classified according to the Global Use of Strategies to Open Occluded Coronary Arteries (GUSTO) criteria for severe or life-threatening, moderate, or mild bleeding. ${ }^{18}$ We obtained 30-day follow-up for $100 \%$ of patients included in the registry.

We included all anticoagulant medications administered for prophylaxis and treatment of thromboembolic events. ADEs associated with the use of the following anticoagulants were reviewed: unfractionated heparin, low-molecular weight heparin, fondaparinux, warfarin, and direct thrombin inhibitors, such as argatroban, bivalirudin, and lepirudin. A multidisciplinary team, including physicians, pharmacists, and a hospital patient safety officer, reviewed all reported anticoagulant-related events and evaluated the root case of all ADEs.

We also collected data regarding the cost associated with hospitalizations in which ADEs occurred. Since medication errors that do not culminate in an ADR do not add significant incremental cost to hospitalization, we only included ADRs in our cost analysis. ADRs that added significant incremental cost to hospitalization were distinguished from those that did not by consensus of a physician (G.P), pharmacist (T.N.N.), and patient safety officer (K.F.). While patients may have suffered multiple ADRs during a hospital admission, we analyzed costs incurred after the initial event. We utilized a software program for cost accounting that is capable of tabulating the cost associated with a patient admission (Transitions System Incorporated, Waltham, MA). We sorted costs by the following categories: nursing, pharmacy, blood products, clinical laboratory, radiology, surgery, non-surgical intervention, and anesthesia. We compared total and component costs of hospitalization for admissions in which an ADR occurred and added incremental expense with those for admissions in which an ADR occurred but was not determined to incur incremental cost.

\section{Statistical methods}

Descriptive statistics including baseline characteristics, variables related to ADEs, and those pertaining to outcomes were stratified as continuous or binary. Continuous variables were presented as medians with interquartile ranges. Binary variables were presented as numbers and proportions. Cost variables were presented as means with standard deviations and were compared using a two-sample t-test. All reported p-values were two-sided, and a p-value of less than 0.05 was considered statistically significant. All statistical analyses were performed using STATA version 9.2 (STATA Corp., College Station, TX).

\section{Results}

\section{Baseline characteristics}

Patients who suffered anticoagulant-associated ADEs had a median age of 62 years (Table 1). Their median body mass index (BMI) was $27.4 \mathrm{~kg} / \mathrm{m}^{2}$. Patients who suffered anticoagulant-associated ADEs had a median length of stay of 13 days. Patients with anticoagulant-associated ADEs had a high frequency of medical conditions, such as atrial 
fibrillation, history of DVT or PE, heart failure, ischemic heart disease, chronic kidney disease, and stroke, that increase the risk of thromboembolism.

\section{Characteristics of anticoagulant-associated adverse drug events}

In 250,725 admissions over the five-year study period, there were 463 anticoagulantassociated ADEs reported. Of these anticoagulant-associated ADEs, 226 were medication errors (48.8\%), 141 were ADRs (30.5\%), and 96 (20.7\%) involved both a medication error and ADR. Seventy percent of anticoagulant-associated ADEs were potentially preventable (Table 2). Unfractionated heparin (58\%) and warfarin (21\%) comprised the most commonly implicated drugs in anticoagulant-associated ADEs. An average of 1.4 anticoagulantassociated ADEs occurred per patient over the five-year study period.

\section{Characteristics of anticoagulant-associated medication errors}

The most frequent type of anticoagulant-associated medication errors were missed medication doses (25\%) and wrong rate or frequency (23\%) (Table 3). Transcription errors (48\%) were the most frequent root cause of anticoagulant-associated medication errors followed by memory lapses (16\%).

\section{Characteristics of anticoagulant-associated adverse drug reactions}

The most frequent anticoagulant-associated ADRs were abnormal coagulation studies (28\%), any bleeding (25\%), and thrombocytopenia (18\%) (Table 4). Seventy two percent of all ADRs were associated with at least one occurrence of excessive anticoagulation, such as a supertherapeutic International Normalized Ratio (INR) or activated partial thromboplastin time (aPTT). Seventeen percent of anticoagulant-associated ADRs culminated in transfusion of at least one unit of packed red blood cells. Undetected predisposing conditions (58\%), such as a previously unknown drug allergy, and medication errors (40\%) comprised the most common root causes of anticoagulant-associated ADRs.

\section{Outcomes of anticoagulant-associated adverse drug events}

Death within 30 days of anticoagulant-associated ADEs occurred in $11 \%$ of patients. Inhospital death occurred after $5.6 \%$ of anticoagulant-associated ADEs, while death after discharge but within 30 days of the ADE was observed in 5\% (Table 5). A rehabilitation center stay was frequently required (40\%) after an admission in which an anticoagulantassociated ADE occurred. Patients who suffered anticoagulant-associated ADEs had a high rate of re-hospitalization within 30 days of the $\mathrm{ADE}(17.5 \%)$.

\section{Cost analysis of anticoagulant-associated adverse drug reactions}

Most hospitalization expenditures after an anticoagulant-associated ADR were attributable to nursing costs (mean $\$ 33,189$ per ADR) followed by pharmacy costs (mean $\$ 7,451$ per ADR) (Table 6). ADRs which were determined to add incremental expense were associated with significant increases in total hospitalization cost (mean $\$ 118,429$ vs. $\$ 54,858, p=0.02$ ) as well as cost after the ADR (mean $\$ 89,733$ vs. $\$ 23,680, p=0.004$ ) compared with ADRs in which no incremental cost was determined to be incurred (Table 7). ADRs which were determined to add incremental cost to hospitalization were associated with significant increases in costs of nursing, pharmacy, blood products, clinical laboratory, and radiology.

\section{Discussion}

We found that $48.8 \%$ of anticoagulant-associated ADEs were medication errors, $30.5 \%$ were ADRs, and $20.7 \%$ involved both medication errors and ADRs. Seventy percent of all reported anticoagulant-associated ADEs were potentially preventable. Transcription errors 
were the most common root cause of medication errors, while undetected predisposing conditions and medication errors were the most frequent root causes of ADRs. We noted high 30-day mortality (11\%) in patients who experienced an anticoagulant-associated ADE during hospitalization. We observed high post-ADE hospitalization costs, largely attributable to nursing and pharmacy expenditures.

We had implemented computerized provider order entry, an electronic medication administration record, "smart" infusion pumps, and bar code technology before the registry was instituted. Therefore, we were surprised to observe that $70 \%$ of anticoagulant-associated ADEs were potentially preventable and that $40 \%$ of related ADRs were due to medication errors. Our data corroborate previous reports demonstrating that a substantial proportion of ADEs are due to medication errors and therefore potentially preventable. ${ }^{4,5}$ Computerized provider order entry, ${ }^{5}$ improved infusion pump technology, ${ }^{11}$ and implementing bar code technology $y^{8,9}$ reduce medication errors. However, our root cause analysis suggests that further improvements can be made to reduce anticoagulant-associated medication errors, particularly those due to transcription errors. While computerized provider order entry, "smart" infusion pump technology, electronic medication administration records, and bar code technology reduce the frequency of some transcription errors, human error may occur at transition points among these clinical tools and result in mistakes at any number of steps in medication transcription. The emergence of novel oral anticoagulants that are administered in fixed doses may further reduce dosing and infusion pump errors. ${ }^{19}$

We observed high 30-day mortality (11\%) in patients suffering an anticoagulant-associated ADE during hospitalization. We speculate that this may be related to a combination of high medical acuity of patients suffering anticoagulant-associated ADEs and complications of the ADEs themselves. Patients with anticoagulant-associated ADEs had a high frequency of medical conditions, such as heart failure, ischemic heart disease, chronic kidney disease, and stroke, all of which may increase patient vulnerability to the complications of anticoagulantassociated ADEs. Furthermore, anticoagulant-associated ADEs may be a marker for fragile patients with complicated hospital courses and long lengths of stay. The contribution of medical errors, including those associated with ADEs, to deaths occurring during hospitalization may be overestimated in studies relying on physician review. ${ }^{20}$ Regardless of whether anticoagulant-associated ADEs contribute to increased mortality or are markers for higher medical acuity, patients who suffer these events represent a particularly vulnerable population. Accordingly, Quality Improvement initiatives to reduce anticoagulant-associated ADEs are critical.

Most hospitalization costs after an anticoagulant-associated ADE were attributable to nursing and pharmacy expenses. ADRs that incurred incremental cost doubled the total hospitalization costs and nearly quadrupled post-event costs compared with ADRs that did not incur any incremental expense. Our findings are similar to other reports that demonstrate the heavy financial burden of ADEs. ${ }^{13,21,22}$ Based on these data, efforts to reduce anticoagulant-associated ADEs have the potential to reduce hospitalization costs as well as improve patient safety.

Our data were obtained from a voluntary patient safety reporting system and therefore may be limited by underreporting and selective reporting, in which only the most severe ADEs or those with the greatest consequences are reported. Because we excluded patient care areas in which medication administration records were not consistently computerized, we may have omitted subgroups of patients who had suffered a higher proportion of anticoagulantassociated ADEs. Because anticoagulant medications are given throughout the hospital but not all patient care areas have electronic medication administration records, it is not possible to calculate the denominator of patients exposed to anticoagulants. Therefore, we could not 
calculate the incidence of anticoagulant-associated ADEs and could not identify an appropriate comparison population of patients exposed to anticoagulant drugs who did not suffer ADEs. In addition, our analysis did not encompass community-acquired ADEs that resulted in hospitalization. While five deaths were clearly attributable to ADE-related bleeding (1) or thromboembolism (4), we were not able to quantify the contribution of ADEs to other deaths in this cohort. Finally, because of limitations in our cost accounting software, we were unable to separate costs incurred after the initial ADR from costs associated with subsequent events in a particular patient during the same hospitalization.

The methodology utilized in this analysis is consistent with published criteria for evaluating the scientific value of clinical data registries. ${ }^{23}$ We utilized a large database generated from a tertiary care center that is representative of similar acute care facilities. Our study provides real-world insights into anticoagulant-associated ADEs from a medical center that has implemented an EHR that integrates computerized provider order entry, an electronic medication administration record, "smart" infusion pumps, and bar code technology. We utilized a multidisciplinary group of physicians, pharmacists, and a patient safety officer to provide the highest accuracy for classifying events and determining root causes of ADEs. Finally, we provided outcomes data for patients who suffered anticoagulant-associated ADEs with $100 \%$ follow-up.

\title{
Conclusions
}

Most anticoagulant-associated ADEs among inpatients result from medication errors and are therefore potentially preventable. Transcription errors are the most common cause of medication errors which, in turn, are a frequent cause of anticoagulant-associated ADRs. We observed elevated 30-day mortality among patients who suffered an anticoagulantassociated ADE and high hospitalization costs following ADRs. Further efforts to reduce anticoagulant-associated medication errors are warranted to improve patient safety and decrease health care expenditures.

\section{Acknowledgments}

\author{
None. \\ Funding Sources \\ Lung, and Blood Institute (NHLBI).

$\begin{array}{ll}\text { ADE } & \text { adverse drug event } \\ \text { ADR } & \text { adverse drug reaction } \\ \text { aPTT } & \text { activated partial thromboplastin time } \\ \text { EHR } & \text { Electronic Health Record } \\ \text { INR } & \text { International Normalized Ratio }\end{array}$

Dr. Piazza is supported by a Research Career Development Award (K12 HL083786) from the National Heart,

This study was funded, in part, by a clinical research grant from Johnson \& Johnson.

\section{Abbreviations}




\section{References}

1. Zaidenstein R, Eyal S, Efrati S, et al. Adverse drug events in hospitalized patients treated with cardiovascular drugs and anticoagulants. Pharmacoepidemiol Drug Saf. 2002; 11:235-238. [PubMed: 12051123]

2. Silverman JB, Stapinski CD, Churchill WW, et al. Multifaceted approach to reducing preventable adverse drug events. Am J Health Syst Pharm. 2003; 60:582-586. [PubMed: 12659063]

3. Piazza G, Goldhaber SZ. Computerized decision support for the cardiovascular clinician: applications for venous thromboembolism prevention and beyond. Circulation. 2009; 120:11331137. [PubMed: 19770412]

4. Morimoto T, Sakuma M, Matsui K, et al. Incidence of Adverse Drug Events and Medication Errors in Japan: the JADE Study. J Gen Intern Med. 2010; 26:148-153. [PubMed: 20872082]

5. Hug BL, Witkowski DJ, Sox CM, et al. Adverse drug event rates in six community hospitals and the potential impact of computerized physician order entry for prevention. J Gen Intern Med. 2009; 25:31-38. [PubMed: 19894081]

6. Classen DC, Jaser L, Budnitz DS. Adverse drug events among hospitalized Medicare patients: epidemiology and national estimates from a new approach to surveillance. Jt Comm J Qual Patient Saf. 2010; 36:12-21. [PubMed: 20112660]

7. Bates DW, Cullen DJ, Laird N, et al. Incidence of adverse drug events and potential adverse drug events. Implications for prevention. ADE Prevention Study Group. JAMA. 1995; 274:29-34. [PubMed: 7791255]

8. Poon EG, Keohane CA, Yoon CS, et al. Effect of bar-code technology on the safety of medication administration. N Engl J Med. 2010; 362:1698-1707. [PubMed: 20445181]

9. Poon EG, Cina JL, Churchill W, et al. Medication dispensing errors and potential adverse drug events before and after implementing bar code technology in the pharmacy. Ann Intern Med. 2006; 145:426-434. [PubMed: 16983130]

10. Leape LL, Bates DW, Cullen DJ, et al. Systems analysis of adverse drug events. ADE Prevention Study Group. JAMA. 1995; 274:35-43. [PubMed: 7791256]

11. Grissinger MC, Hicks RW, Keroack MA, et al. Harmful medication errors involving unfractionated and low-molecular-weight heparin in three patient safety reporting programs. Jt Comm J Qual Patient Saf. 2010; 36:195-202. [PubMed: 20480751]

12. Fanikos J, Stapinski C, Koo S, et al. Medication errors associated with anticoagulant therapy in the hospital. Am J Cardiol. 2004; 94:532-535. [PubMed: 15325949]

13. Bates DW, Spell N, Cullen DJ, et al. The costs of adverse drug events in hospitalized patients. Adverse Drug Events Prevention Study Group. JAMA. 1997; 277:307-311. [PubMed: 9002493]

14. Fanikos J, Cina JL, Baroletti S, et al. Adverse drug events in hospitalized cardiac patients. Am J Cardiol. 2007; 100:1465-1469. [PubMed: 17950809]

15. Hanlon JT, Pieper CF, Hajjar ER, et al. Incidence and predictors of all and preventable adverse drug reactions in frail elderly persons after hospital stay. J Gerontol A Biol Sci Med Sci. 2006; 61:511-515. [PubMed: 16720750]

16. Hajjar ER, Hanlon JT, Artz MB, et al. Adverse drug reaction risk factors in older outpatients. Am J Geriatr Pharmacother. 2003; 1:82-89. [PubMed: 15555470]

17. Nebeker JR, Barach P, Samore MH. Clarifying adverse drug events: a clinician's guide to terminology, documentation, and reporting. Ann Intern Med. 2004; 140:795-801. [PubMed: 15148066]

18. The GUSTO investigators. An international randomized trial comparing four thrombolytic strategies for acute myocardial infarction. N Engl J Med. 1993; 329:673-682. [PubMed: 8204123]

19. Eikelboom JW, Weitz JI. New anticoagulants. Circulation. 2010; 121:1523-1532. [PubMed: 20368532]

20. Hayward RA, Hofer TP. Estimating hospital deaths due to medical errors: preventability is in the eye of the reviewer. Jama. 2001; 286:415-420. [PubMed: 11466119]

21. Jennings HR, Miller EC, Williams TS, et al. Reducing anticoagulant medication adverse vents and avoidable patient harm. Jt Comm J Qual Patient Saf. 2008; 34:196-200. [PubMed: 18468356] 
22. Eckman MH, Levine HJ, Pauker SG. Making decisions about antithrombotic therapy in heart disease. Decision analytic and cost-effectiveness issues. Chest. 1995; 108:457S-470S. [PubMed: 7555196]

23. Alpert JS. Are data from clinical registries of any value? Eur Heart J. 2000; 21:1399-1401. [PubMed: 10952831] 
Table 1

Baseline characteristics and medical conditions in patients with anticoagulation-associated adverse drug events (ADEs) $(\mathrm{n}=463)$.

\begin{tabular}{|c|c|}
\hline Baseline characteristic & \\
\hline Median age on admission, years (interquartile range) & $62(49-72)$ \\
\hline Age $>75$ years, $n(\%)$ & $92(19.9)$ \\
\hline Male, n (\%) & $246(53.1)$ \\
\hline Median body mass index, $\mathrm{kg} / \mathrm{m}^{2}$ (interquartile range) & $27.4(23.8-33.1)$ \\
\hline Median length of stay, $d$ (interquartile range) & $13(7-23)$ \\
\hline \multicolumn{2}{|l|}{ Medical condition } \\
\hline Hypertension, n (\%) & $243(52.5)$ \\
\hline Surgery in past 2 months, $\mathrm{n}(\%)$ & $213(46)$ \\
\hline Ischemic heart disease, $\mathrm{n}(\%)$ & $140(30.2)$ \\
\hline Atrial fibrillation, n (\%) & $126(27.2)$ \\
\hline Serum creatinine $>1.5 \mathrm{mg} / \mathrm{dL}, \mathrm{n}(\%)$ & $125(27)$ \\
\hline Deep vein thrombosis or pulmonary embolism, n (\%) & $121(26.1)$ \\
\hline Heart failure, n (\%) & $106(22.9)$ \\
\hline Diabetes, n $(\%)$ & $104(22.5)$ \\
\hline Active cancer without metastases, n (\%) & $74(16)$ \\
\hline Status post heart valve surgery, n (\%) & $68(14.7)$ \\
\hline Chronic obstructive pulmonary disease, n (\%) & $66(14.3)$ \\
\hline History of stroke, n (\%) & $45(9.7)$ \\
\hline Active cancer with metastases, n (\%) & $42(9.1)$ \\
\hline Other thromboembolism, n (\%) & $40(8.6)$ \\
\hline History of cancer, n (\%) & $34(7.3)$ \\
\hline Dialysis, n (\%) & $30(6.5)$ \\
\hline Thrombophilia, n (\%) & $16(3.5)$ \\
\hline
\end{tabular}

* Patients could have had more than one ADE.

ADE, adverse drug event. 
Table 2

Characteristics of adverse drug events (ADEs) in patients receiving anticoagulation $(\mathrm{n}=463){ }^{*}$

\begin{tabular}{|l|l|}
\hline Characteristic of ADE & \\
\hline Adverse drug reaction (ADR), $\mathrm{n}(\%)$ & $141(30.5)$ \\
\hline Medication error, $\mathrm{n}(\%)$ & $226(48.8)$ \\
\hline Combined medication error and ADR, $\mathrm{n}(\%)$ & $96(20.7)$ \\
\hline Near miss, $\mathrm{n}(\%)$ & $33(7.1)$ \\
\hline Potentially preventable ADE, $\mathrm{n}(\%)$ & $322(69.5)$ \\
\hline Anticoagulant associated with ADE & \\
\hline Unfractionated heparin, $\mathrm{n}(\%)$ & $270(58.3)$ \\
\hline Warfarin, $\mathrm{n}(\%)$ & $96(20.7)$ \\
\hline Low-molecular weight heparin, $\mathrm{n}(\%)$ & $44(9.5)$ \\
\hline Argatroban, $\mathrm{n}(\%)$ & $29(6.3)$ \\
\hline Bivalirudin, $\mathrm{n}(\%)$ & $18(3.9)$ \\
\hline Lepirudin, $\mathrm{n}(\%)$ & $3(0.7)$ \\
\hline Fondaparinux, $\mathrm{n}(\%)$ & $3(0.7)$ \\
\hline
\end{tabular}

* Patients could have had more than one ADE including both medication errors and ADRs.

ADE, adverse drug event; ADR, adverse drug reaction 
Table 3

Types and root causes of anticoagulant-associated medication errors $(n=323)$.

\begin{tabular}{|l|l|}
\hline Type of medication error ${ }^{*}$ & \\
\hline Missed dose, $\mathrm{n}(\%)$ & $79(24.5)$ \\
\hline Wrong rate or frequency, $\mathrm{n}(\%)$ & $75(23.2)$ \\
\hline Medication not discontinued when ordered, $\mathrm{n}(\%)$ & $31(9.6)$ \\
\hline Extra dose, $\mathrm{n}(\%)$ & $26(8.1)$ \\
\hline Wrong dose, $\mathrm{n}(\%)$ & $23(7.1)$ \\
\hline Wrong time of administration, $\mathrm{n}(\%)$ & $17(5.3)$ \\
\hline Failure to act on laboratory result, $\mathrm{n}(\%)$ & $17(5.3)$ \\
\hline Known allergy or contraindication, $\mathrm{n}(\%)$ & $13(4)$ \\
\hline Wrong route, $\mathrm{n}(\%)$ & $10(3.1)$ \\
\hline Medication expired, $\mathrm{n}(\%)$ & $8(2.5)$ \\
\hline Wrong patient, $\mathrm{n}(\%)$ & $7(2.2)$ \\
\hline Wrong drug, $\mathrm{n}(\%)$ & $7(2.2)$ \\
\hline Preparation error, $\mathrm{n}(\%)$ & $6(1.9)$ \\
\hline Wrong technique of administration, $\mathrm{n}(\%)$ & $3(0.9)$ \\
\hline Medication administered without an order, $\mathrm{n}(\%)$ & $2(0.6)$ \\
\hline Inadequate monitoring, $\mathrm{n}(\%)$ & $1(0.3)$ \\
\hline Root cause of medication error & $1(0.3)$ \\
\hline Transcription error, $\mathrm{n}(\%)$ & $1(0.3)$ \\
\hline Memory lapse, $\mathrm{n}(\%)$ & $155(48)$ \\
\hline Infusion or parenteral administration problem, $\mathrm{n}(\%)$ & $28(8.7)$ \\
\hline Rule violation, $\mathrm{n}(\%)$ & $19(5.9)$ \\
\hline Lack of knowledge about drug, $\mathrm{n}(\%)$ & $18(5.6)$ \\
\hline Faulty drug identity checking, $\mathrm{n}(\%)$ & $17(5.3)$ \\
\hline Drug preparation error, $\mathrm{n}(\%)$ & $12(3.7)$ \\
\hline Drug stocking or delivery problem, $\mathrm{n}(\%)$ & $9(2.8)$ \\
\hline Faulty interaction between services, $\mathrm{n}(\%)$ & $(1.2)$ \\
\hline Lack of information about the patient, $\mathrm{n}(\%)$ & $(\%)$ \\
\hline Faulty dose checking, $\mathrm{n}(\%)$ & $(\%)$ \\
\hline Known allergy or contraindication, $\mathrm{n}(\%)$ & $(\%)$ \\
\hline
\end{tabular}

Patients may have had more than one medication error type. 
Table 4

Characteristics and root causes of adverse drug reactions (ADRs) $(n=238)$.

\begin{tabular}{|c|c|}
\hline Characteristic of ADR & \\
\hline Abnormal coagulation studies, $\mathrm{n}(\%)$ & $48(27.9)$ \\
\hline Occurrences of excessive anticoagulation during hospitalization, $\mathrm{n}(\%)$ & $171(71.9)$ \\
\hline Any bleeding event, $\mathrm{n}(\%)$ & $59(24.8)$ \\
\hline Occult bleed & $21(8.8)$ \\
\hline Bleeding event related to surgery & $14(5.9)$ \\
\hline Hematoma & $8(3.4)$ \\
\hline Any gastrointestinal bleeding & $6(2.5)$ \\
\hline Decrease in hematocrit & $6(2.5)$ \\
\hline Retroperitoneal hemorrhage & $3(1.3)$ \\
\hline Median length of stay post bleeding event, $\mathrm{d}$ (interquartile range) & $9(5-20)$ \\
\hline Blood transfusion administered, $\mathrm{n}(\%)$ & $40(16.8)$ \\
\hline Blood transfusion administered with 48 hours after surgery, $\mathrm{n}(\%)$ & $13(5.5)$ \\
\hline \multicolumn{2}{|l|}{ Treatment of bleeding ADR, $\mathrm{n}(\%)$} \\
\hline Vitamin $\mathrm{K}$ & $10(4.2)$ \\
\hline Protamine & $2(0.8)$ \\
\hline Fresh frozen plasma & $11(4.6)$ \\
\hline Surgery & $6(2.5)$ \\
\hline Catheterization laboratory & $1(0.4)$ \\
\hline \multicolumn{2}{|l|}{ GUSTO bleeding classification, $\mathrm{n}(\%)$} \\
\hline I & $19(8)$ \\
\hline II & $32(13.5)$ \\
\hline III & $8(3.4)$ \\
\hline Thrombocytopenia, n (\%) & $43(18.1)$ \\
\hline Heparin-induced thrombocytopenia, n (\%) & $31(13)$ \\
\hline Any thromboembolic event, $\mathrm{n}(\%)$ & $16(6.7)$ \\
\hline Deep vein thrombosis & $6(2.5)$ \\
\hline Pulmonary embolism & $6(2.5)$ \\
\hline Myocardial infarction & $1(0.4)$ \\
\hline Stroke & $2(0.8)$ \\
\hline Other arterial thromboembolic event & $1(0.4)$ \\
\hline Thromboembolic ADR requiring treatment, $\mathrm{n}(\%)$ & $8(3.4)$ \\
\hline \multicolumn{2}{|l|}{ Treatment of thromboembolic ADR, n (\%) } \\
\hline Catheterization laboratory & $3(1.3)$ \\
\hline
\end{tabular}




$\mid$\begin{tabular}{l|l} 
Interventional radiology procedure & $1(0.4)$ \\
Surgery & $2(0.8)$ \\
\hline Root cause of ADR & $138(58)$ \\
\hline Undetected predisposing condition, $\mathrm{n}(\%)$ & $94(39.5)$ \\
\hline Medication error, $\mathrm{n}(\%)$ & $3(1.3)$ \\
\hline Drug-drug interaction, $\mathrm{n}(\%)$ & $2(0.8)$ \\
\hline Patient medication non-adherence, $\mathrm{n}(\%)$ &
\end{tabular}

ADR, adverse drug reaction 
Table 5

Outcomes of adverse drug events (ADEs) $(n=463)$.

\begin{tabular}{|l|l|}
\hline Outcome & \\
\hline In-hospital death, n (\%) & $26(5.6)$ \\
\hline Death after discharge but within 30 days of ADE, n (\%) & $23(5)$ \\
\hline Death due to thromboembolism, n (\%) & $4(0.9)$ \\
\hline Death due to bleeding event, n (\%) & $1(0.2)$ \\
\hline Discharge status, n (\%) & $236(51)$ \\
Home & $186(40.2)$ \\
Rehabilitation center & $13(2.8)$ \\
Hospice & $2(0.4)$ \\
Acute care facility & $26(5.6)$ \\
Deceased & $81(17.5)$ \\
\hline Readmission within 30 days of ADE, n (\%)
\end{tabular}

ADE, adverse drug event 
Table 6

Cost associated with adverse drug reactions (ADRs). ${ }^{*}$

\begin{tabular}{|l|c|}
\hline Overall and departmental costs & Mean $\mathbf{( \$ )} \pm$ standard deviation $^{* *}$ \\
\hline Total hospitalization & $88842 \pm 166708$ \\
\hline Hospitalization pre-ADR & $29851 \pm 49264$ \\
\hline Hospitalization post-ADR & $58991 \pm 146065$ \\
\hline Nursing & $33189 \pm 81236$ \\
\hline Pharmacy & $7451 \pm 21878$ \\
\hline Blood products & $2318 \pm 9235$ \\
\hline Clinical laboratory & $2001 \pm 5069$ \\
\hline Radiology & $1864 \pm 4175$ \\
\hline Surgical & $225 \pm 1349$ \\
\hline Interventional procedure & $210 \pm 1485$ \\
\hline Anesthesia & $46 \pm 257$ \\
\hline Drug-related costs & $1570 \pm 7097$ \\
\hline Argatroban & $1102 \pm 5879$ \\
\hline Bivalirudin & $87 \pm 579$ \\
\hline Thrombolytic therapy & $49 \pm 154$ \\
\hline Low-molecular weight heparin & $35 \pm 64$ \\
\hline Unfractionated heparin & $34 \pm 327$ \\
\hline Lepirudin & $23 \pm 45$ \\
\hline Warfarin & $14 \pm 76$ \\
\hline Fondaparinux & $4 \pm 51$ \\
\hline Aprotinin & $2 \pm 6$ \\
\hline Vitamin K & $2 \pm 12$ \\
\hline Desmopressin & $1 \pm 6$ \\
\hline Protamine & $0 \pm 1$ \\
\hline Aminocaproic acid & \\
\hline
\end{tabular}

ADR, adverse drug reaction

* Patients may have suffered multiple ADRs during a hospital admission. Costs incurred were analyzed after the initial event. **

Costs are rounded to the nearest U.S. dollar. 
Table 7

Incremental cost associated with adverse drug reactions (ADRs). ${ }^{*}$

\begin{tabular}{|c|c|c|c|}
\hline Overall and departmental costs (Mean \pm standard deviation) ${ }^{* * *}$ & No incremental cost $(\mathrm{n}=\mathbf{8 5})$ & Incremental cost $(n=74)$ & p-value \\
\hline Total hospitalization & $54858 \pm 115659$ & $118429 \pm 196840$ & 0.02 \\
\hline Hospitalization pre-ADR & $31178 \pm 58172$ & $28696 \pm 40265$ & 0.75 \\
\hline Hospitalization post-ADR & $23680 \pm 65283$ & $89733 \pm 185395$ & 0.004 \\
\hline Nursing & $14008 \pm 42457$ & $49888 \pm 101194$ & 0.005 \\
\hline Pharmacy & $2830 \pm 9243$ & $11473 \pm 28123$ & 0.01 \\
\hline Blood products & $548 \pm 1703$ & $3858 \pm 12359$ & 0.02 \\
\hline Clinical laboratory & $902 \pm 2469$ & $2957 \pm 6406$ & 0.01 \\
\hline Radiology & $798 \pm 2228$ & $2792 \pm 5158$ & 0.002 \\
\hline Surgical & $0 \pm 0$ & $421 \pm 1828$ & 0.0496 \\
\hline Interventional procedure & $0 \pm 0$ & $393 \pm 2019$ & 0.1 \\
\hline Anesthesia & $0 \pm 0$ & $87 \pm 348$ & 0.03 \\
\hline \multicolumn{4}{|l|}{ Drug-related costs } \\
\hline Argatroban & $231 \pm 1441$ & $2735 \pm 9486$ & 0.03 \\
\hline Bivalirudin & $70 \pm 366$ & $2001 \pm 7946$ & 0.04 \\
\hline Thrombolytic therapy & $24 \pm 205$ & $142 \pm 766$ & 0.2 \\
\hline Lepirudin & $0 \pm 0$ & $63 \pm 446$ & 0.23 \\
\hline Low-molecular weight heparin & $53 \pm 183$ & $45 \pm 125$ & 0.72 \\
\hline Unfractionated heparin & $27 \pm 67$ & $41 \pm 60$ & 0.14 \\
\hline Warfarin & $15 \pm 43$ & $30 \pm 47$ & 0.04 \\
\hline Fondaparinux & $0 \pm 4$ & $26 \pm 102$ & 0.03 \\
\hline Aprotinin & $0 \pm 0$ & $8 \pm 69$ & 0.35 \\
\hline Vitamin $\mathrm{K}$ & $1 \pm 5$ & $3 \pm 7$ & 0.01 \\
\hline Desmopressin & $0 \pm 0$ & $3 \pm 17$ & 0.17 \\
\hline Protamine & $0 \pm 0$ & $3 \pm 8$ & 0.003 \\
\hline Aminocaproic acid & $0 \pm 0$ & $0 \pm 1$ & 0.21 \\
\hline
\end{tabular}

ADR, adverse drug reaction

* Patients may have suffered multiple ADRs during a hospital admission. Costs incurred were analyzed after the initial event. **

Costs are rounded to the nearest U.S. dollar. 